\title{
O AMIGO IMAGINÁRIO NA VISÃO DE PSICÓLOGOS E PSIQUIATRAS INFANTIS
}

THE IMAGINARY FRIEND IN THE VIEW OF CHILD PSYCHOLOGISTS AND PSYCHIATRISTS
EL AMIGO IMAGINARIO EN EL PUNTO DE VISTA DE PSICÓLOGOS Y PSIQUIATRAS DE NIÑOS

\author{
Juliana Marion* \\ Angélica Dotto Londero ${ }^{* *}$ \\ Caroline Rubin Rossato Pereira ${ }^{* * *}$ \\ Ana Paula Ramos de Souza $a^{* * * *}$
}

\begin{abstract}
RESUMO
Esta pesquisa buscou compreender como os profissionais da área de Psicologia e Psiquiatria, com atuação na clínica infantil, entendem a presença do fenômeno do amigo imaginário na infância. Três psicólogos e dois psiquiatras com cinco anos ou mais de experiência foram entrevistados sobre suas práticas profissionais. Os participantes foram recrutados em clínicas de atendimento à criança em uma cidade do interior do Rio Grande do Sul. A análise de conteúdo indicou que os profissionais consideravam o fenômeno um acontecimento saudável do desenvolvimento e facilmente diferenciável da sintomatologia da psicose. Além disso, acreditavam que a fantasia poderia servir como um recurso para o profissional investigar a realidade psíquica da criança, facilitando a comunicação nos atendimentos. Com base nesses resultados, buscou-se contribuir com a literatura nacional acerca do tema, ainda escassa, e com a atuação e conhecimento dos profissionais da área de saúde infantil e todos aqueles que estão em constante contato com crianças (profissionais escolares, familiares, etc.).
\end{abstract}

Palavras-chave: Amigo imaginário. Desenvolvimento infantil. Psicose. Imaginação infantil.

\footnotetext{
ABSTRACT

This research meant to understand how professionals in Psychology and Psychiatry, working in child clinic, understand the presence of the

Texto recebido em 19 de agosto de 2015 e aprovado para publicação em 15 de setembro de 2016.

Mestranda em Psicologia pelo Programa de Pós-Graduação da Universidade Federal de Santa Maria (UFSM), bolsista CAPES,

** Mestra em Psicologia Clínica pela PUC-RS, professora no Departamento de Psicologia da UFSM. E-mail: angelicadl2006@

*** Doutora em Psicologia pela Universidade Federal do Rio Grande do Sul (UFRGS), especialista em Psicologia Clínica pelo Instituto da Família de Porto Alegre (Infapa), professora no Programa de Pós-Graduação em Psicologia da UFSM. E-mail:

${ }^{* * * *}$ Pós-doutora em Letras pela UFRGS, docente do Programa de Pós-Graduação em Distúrbios da Comunicação Humana e Programa de Pós-graduação em Psicologia da UFSM. E-mail: ramos1964@uol.com.br.
} psicóloga.E-mail: julianamarion@live.com. hotmail.com. carolinerrp@ufsm.br. 
imaginary friend phenomenon in childhood. Three psychologists and two psychiatrists with five or more years of experience were interviewed about their professional practices. Participants were recruited at clinical care for children in a city in the countryside of Rio Grande do Sul State. The content analysis indicated that the professionals considered the phenomenon as a healthy development event and easily distinguishable from symptoms of psychosis. Moreover, they believed that fantasy could serve as a resource for professionals to investigate the psychic reality of the child, facilitating communication during care. From these results, we sought to contribute to the scarce national literature on the subject, to the practice and knowledge of professionals in children health, as well as to all of those who are in constant contact with children (school professionals, family members, etc.).

Keywords: Imaginary friend. Child development. Psychosis. Children's imagination.

\section{RESUMEN}

Esta investigación buscó comprender cómo los profesionales del área de la Psicología y Psiquiatría, que actúan en la clínica infantil, entienden la presencia del fenómeno del amigo imaginario en la niñez. Tres psicólogos y dos psiquiatras, con cinco o más años de experiencia, fueron entrevistados acerca de sus prácticas profesionales. Los participantes fueron reclutados en clínicas de atención a los niños en una ciudad del interior de Rio Grande do Sul, estado ubicado en la región sur de Brasil. El análisis de contenido indicó que los profesionales consideraban el fenómeno un acontecimiento sano en el desarrollo y fácilmente diferenciable de los síntomas de la psicosis. Además, creían que la fantasía puede servir como un recurso para que los profesionales investiguen la realidad psíquica del niño, facilitando la comunicación en la atención a ellos. A partir de estos resultados, hemos tratado de contribuir a la literatura sobre el tema en Brasil, todavía escasa, y a la actuación y el conocimiento de los profesionales en el área de la salud del niño y todos los que están en constante contacto con los niños (profesionales de la escuela, miembros de la familia, etc.).

Palabras clave: Amigo imaginario. El desarrollo del niño. Psicosis. Imaginación infantil.

\section{INTRODUÇÃO}

literatura psicológica aponta que a vivência de um amigo imaginário é
frequente na infância e pode ser um componente do desenvolvimento
infantil saudável (Klein, 1985; Majors, 2013; Shapiro, Prince, Ireland 
\& Stein, 2006; Singer \& Singer, 1990; Taylor, 1999; Taylor \& Mottweiler, 2008). Esta pesquisa buscou investigar se há diferenças e traços compartilhados entre a saúde e a patologia, mais especificamente a psicose infantil, associadas ao fenômeno do amigo imaginário na infância. Contudo esse fenômeno pode ser confundido com a sintomatologia da psicose infantil, podendo gerar um problema para a criança (Shapiro et al., 2006; Taylor, 1999). Dessa forma, torna-se importante aos profissionais que atuam na área da saúde mental infantil reconhecer as diferenças entre a manifestação do amigo imaginário e a psicose.

\section{$1.1 \mathrm{O}$ amigo imaginário}

Em um lugar onde o real e o imaginário convivem, o fenômeno do amigo imaginário pode emergir durante a infância. Nesse mundo privado, a criança pode separar sua subjetividade da objetividade do ambiente e, assim, projetar, em sua criação, os seus ideais, medos, agressividade e amor. No decorrer do desenvolvimento, esses sentimentos e ideias são gradualmente integrados à personalidade do indivíduo (Klein, 1985).

O amigo imaginário foi tradicionalmente definido como um personagem invisível que tem nome, é mencionado em conversaçôes com outras pessoas e com o qual a criança mantém interação por, pelo menos, alguns meses. Para ser considerado um amigo imaginário, a criação deve ter um senso de realidade para a criança, mas não ter base objetiva. No entanto, mesmo que se torne tão real quanto uma percepção sensorial visual ou auditiva, seu criador sempre reconhece sua irrealidade (Svendsen, 1934, citado por Pearson et al., 2001). Por sua vez, em uma definição mais abrangente, Taylor (1999), Singer e Singer (1990) e Taylor, Carlson, Maring, Gerow e Charley (2004) incluem na categoria de amigo imaginário aqueles brinquedos personificados, com os quais a criança interage com frequência. Segundo Singer e Singer (1990), para o brinquedo ser considerado um amigo imaginário, ele precisa ser tratado como um amigo e ter qualidades humanas.

Desse modo, fica claro que a literatura psicológica entende o amigo imaginário como uma forma de faz de conta e uma manifestação da imaginação; característica que se faz tão intensa nessa fase do desenvolvimento (Klein, 1985; Majors, 2013; Shapiro et al., 2006; Singer \& Singer, 1990; Taylor, 1999; Taylor \& Mottweiler, 2008). O amigo imaginário é, portanto, apenas uma de muitas formas de a criança expressar sua criatividade (Pearson et al., 2001; Taylor, 1999). De todo modo, o fenômeno também pode ser compreendido com base em perspectivas religiosas espíritas, em que se entende que a criança está diretamente conectada com o mundo espiritual, por ser inocente e livre da culpa do mundo adulto (Singer $\&$ 
Singer, 1990). A pesquisa de Taylor (1999) encontrou, em sua população, $2 \%$ de mães, as quais se identificaram como "cristãs fundamentalistas", que entendiam os amigos imaginários como associados ao maligno. No entanto a autora acredita que pais que seguem essa crença religiosa possam hesitar em participar de pesquisas psicológicas, o que pode resultar em uma porcentagem subestimada. Já a Sociedade Menonita, descendente do cristianismo fundamentalista, considera negativa a interação com amigos imaginários pelo fato de as brincadeiras de faz de conta não estarem diretamente relacionadas com as futuras funçôes que as crianças ocuparão na comunidade (pai, mãe e agricultores) (Taylor, 1999).

A faixa etária dos 2 aos 6 anos de idade é percebida como a mais propícia para a criação de amigos imaginários (Singer \& Singer, 1990). Um estudo com 152 crianças entre 3 e 4 anos de idade encontrou esse faz de conta presente em $28 \%$ da amostra (Taylor, 1999). Três anos depois, cem dessas crianças, agora com idades entre 6 e 7 anos, participaram novamente de pesquisas. Delas, 31\% tinham amigos imaginários (Taylor et al., 2004). Complementando essas informações, dados com crianças dos Estados Unidos indicam que, até os 7 anos, em torno de $65 \%$ delas fazem uso dessa fantasia, sendo $37 \%$ das criações amigos invisíveis e 28\% brinquedos personificados (Taylor \& Mottweiler, 2008).

A maioria dos amigos imaginários de crianças mais velhas (idade média: 4 anos de idade) são invisíveis, enquanto em crianças mais novas (idade média: 6 anos e 9 meses de idade), pelo menos metade dos fenômenos contém sua base em brinquedos (Taylor et al., 2004). Já na adolescência, outros recursos fantasiosos parecem ser utilizados. A pesquisa de Seiffge-Krenke (1997) com 241 adolescentes, entre 12 e 17 anos, encontrou que $40 \%$ deles faziam uso de diários. Desses, um terço dos meninos e $60 \%$ das meninas relatavam suas vivências e endereçavam sua escrita a um interlocutor não real.

A criação de amigos imaginários pode ser erroneamente entendida como sinônimo de perturbação psíquica, tristeza ou solidão, o que leva alguns pais a se preocuparem com o surgimento do fenômeno na vida de seus filhos. A concepção de que as crianças criam amigos imaginários como forma de compensar a falta de amigos reais ou a pobreza dessas interações não se sustenta, pois crianças que têm amigos reais também criam amigos imaginários. Ainda, a interação com esse fenômeno parece auxiliar as crianças a aperfeiçoar suas habilidades sociais (Gleason, 2004). Crianças com amigos imaginários apresentam níveis mais altos de ansiedade, mas dentro da normalidade. Além disso, não há evidências que apontem diferenças entre crianças com ou sem amigos imaginários quanto ao temperamento e às dimensões emocionais de medo e ansiedade (Bouldin \& Pratt, 2002). 
Segundo Taylor (1999), a criação de amigos imaginários também pode ser relacionada, pelo senso comum, com grande potencial criativo e intelectual, abrangendo, por isso, um componente do desenvolvimento emocional e cognitivo. A questão da criatividade foi estudada pela pesquisa de Hoff (2005) de maneira mais focada a partir da aplicação do questionário de atividade (the activity questionnaire), teste de funcionamento criativo (the creative functioning test) e do teste de uso incomum (the unusual uses test). O questionário de atividade busca medir o envolvimento em atividades e hobbies criativos, dentre os quais questiona sobre a criação e interação com amigos imaginários. O teste de funcionamento criativo avalia a flexibilidade cognitiva, que é a habilidade de alternar, de forma flexível, entre o pensamento imaginário e o racional. Já o teste de uso incomum é uma medida de avaliação da fluência de ideias, em que os participantes são convidados a imaginarem quantas formas de utilizar um objeto comum elas conseguirem. A pesquisa contou com 69 crianças suecas de 10 anos de idade, das quais 26 tinham amigos imaginários. Seus resultados indicaram existir relação entre a presença desse fenômeno e um potencial criativo mais elevado, visto que o subgrupo de crianças com amigos imaginários alcançou pontuações mais elevadas no questionário de atividade e no teste de uso incomum, tendo o teste de funcionamento criativo encontrado uma tendência nessa mesma direção. $\mathrm{O}$ estudo de Hoff (2005) também encontrou que as crianças que fazem uso dessa fantasia, quando comparadas àquelas que não interagem com esse fenômeno, descrevem-se como tendo poucos amigos e com um bem-estar psicológico inferior. No entanto esses resultados não são indicativos de patologia.

As características e atividades desenvolvidas com amigo imaginário são dicas sobre o que a criança observa e vivencia em seu ambiente (Taylor, 1999), e a interação com essa fantasia pode ter relação com situações de sua vida (Majors, 2013). Assim, a criação de companhias imaginárias também pode ser vista como uma resposta adaptativa diante de preocupaçóes. Na verdade, a literatura indica que as crianças criam amigos imaginários por diversas razões. A maioria o faz pela diversão e pela companhia (Taylor, 1999). Além disso, esses companheiros servem como apoio para a criança superar medos e períodos de solidão, desenvolver confiança (Majors, 2013; Taylor, 1999). Tais criações também podem ser utilizados para auxiliar a criança a lidar com suas habilidades ou com a falta delas, servindo muitas vezes como bodes expiatórios. Ainda, esse fenômeno ajuda a criança no manejo de dificuldades e limitações encontradas no dia a dia. Por exemplo, os amigos imaginários podem fazer várias coisas que as crianças não estão permitidas a fazer, como dormir tarde e somente se alimentar de salgadinhos e doces (Klein, 1985; Taylor, 1999). Finalmente, eles também podem atuar como facilitadores da comunicação, pois é mais fácil para a criança 
falar de assuntos delicados e de seus sentimentos por meio do amigo imaginário, assim como é mais fácil se expressar através do sussurro com esse companheiro do diretamente a um adulto (Taylor, 1999). Afinal, o amigo imaginário é considerado confiável, constante e compreensivo (Majors, 2013; Taylor, 1999).

Estudos indicam ainda que meninos costumam imaginar amigos com características e habilidades superiores às deles, enquanto as meninas tenderiam a criar amigos com características e habilidades inferiores às suas. Essas informações podem estar relacionadas com os estereótipos de gênero presentes na sociedade, sugerindo que as crianças também se utilizariam do amigo imaginário para lidar com essas questôes. Os meninos colocariam o amigo em um lugar de idealização (mais forte, corajoso, etc.), enquanto as meninas manteriam uma relação de cuidado e tutoria com esse companheiro (ensinar conteúdos escolares, cuidar quando está doente, etc.) (Harter \& Chao, 1992). Para além das diferenças de gênero, os resultados do estudo de Harter e Chao (1992), com 40 crianças em torno dos 6 aos 7 anos de idade, sugeriram que as crianças que têm amigos imaginários seriam menos competentes que seus pares e têm menores níveis de aceitação social.

Apesar das desvantagens apresentadas por essa população em alguns dos estudos citados, como um nível mais elevado de ansiedade (Bouldin \& Pratt, 2002) ou um nível de aceitação social inferior (Harter \& Chao, 1992) que seus pares, acredita-se serem estudos que complementam alguns dos motivos da criação desses amigos, como a companhia que eles oferecem (Taylor, 1999) ou como auxílio em lidar com suas habilidades/inabilidades (Klein, 1985; Taylor, 1999). Dessa forma, os amigos imaginários se mostram como recursos saudáveis utilizados pelas crianças para manejar dificuldades inerentes ao próprio processo de desenvolvimento.

\section{2 $\mathrm{O}$ desenvolvimento infantil e o fenômeno do amigo imaginário}

Neste estudo, optou-se por abordar o processo de desenvolvimento saudável infantil a partir da teoria do amadurecimento emocional proposta por Winnicott. O autor desenvolveu conceitos importantes, como a criatividade, o objeto transicional e a passagem de um estado de ilusão, no qual predomina a realidade subjetiva, para um estado de desilusão, no qual o bebê entra em contato com a realidade objetivamente percebida. Para o autor, a criatividade é o que possibilita ao indivíduo construir uma vida real e significativa (Winnicott, 2000). Ela é proporcionada pela mãe suficientemente boa, que é aquela capaz de exercer uma maternagem que atenda às demandas e aos ritmos do bebê, permitindo o início de seu desenvolvimento pessoal e verdadeiro (Winnicott, 2001b). A criatividade está presente desde o início da vida do bebê e 
continua presente, permitindo ao ser humano criar e recriar a cultura da qual faz parte. O fato de exercer uma ação criativa no mundo dá ao sujeito o sentimento de estar vivo e de uma continuidade da existência (Winnicott, 2000).

Os objetos transicionais tratam-se de objetos que desempenham a função de representar a mãe e possibilitar consolo e conforto à criança nos períodos de ausência materna. Trata-se da primeira possessão, que tem um valor simbólico de união, podendo ser um cobertor, um boneco ou qualquer outro item. O objeto transicional está em uma zona intermediaria, não é de todo externo ou interno, pertencendo ao mundo subjetivo e também à realidade compartilhada, portanto (Winnicott, 1975).

No início da vida, o bebê necessita que o ambiente se adapte totalmente às suas necessidades físicas e emocionais (Abadi, 1998; Winnicott, 1999; 2001b; 2012;), tornando-se suficientemente bom para o bebê. Isso só é possível graças à constância do cuidado materno, que se traduz como uma continuidade da existência do bebê (Winnicott, 2012), proporcionando condiçôes para a integração. A integração surge a partir da não integração, estado no qual todos nascemos, e desenvolve-se a partir das provisões ambientais realizadas pela mãe do bebê. Manifesta-se de forma gradual até o momento em que a criança adquire o status de unidade, o status de indivíduo, de pessoa inteira (Winnicott, 2001b). Em conjunto com a conquista da integração, a criança está em um processo de personalização, no qual ela passa a habitar o próprio corpo. Em paralelo, a apresentação de objetos permite ao bebê a aquisição da capacidade de se relacionar com a realidade, inicialmente subjetiva para posterior e gradativamente perceber objetivamente a realidade externa. Isso somente é possível a partir da desadaptação gradual da mãe em relação ao bebê (Abadi, 1998; Winnicott, 1999).

Fazer com que o ser humano alcance sua unidade, sabendo diferenciar o que lhe é externo e interno, é um dos principais objetivos do desenvolvimento emocional. Entre aquilo que é percebido como subjetivo e objetivo, abre-se um espaço intermediário de experimentação, no qual o indivíduo pode repousar de sua tarefa de manter separada a realidade psíquica da realidade externa, mesmo que essas se encontrem sempre interligadas. É nesse espaço intermediário que, no desenvolvimento saudável, o bebê faz uso de um objeto específico, escolhido a partir do oitavo mês de vida e especial por ter acompanhado a dupla mãe-bebê durante os primeiros meses de vida. Esse caminho descreve a jornada que parte daquilo que é subjetivamente percebido (realidade interna) em direção ao que é objetivamente percebido (realidade externa) (Winnicott, 1975). Esse objeto é chamado de objeto transicional, e sua função é, ao mesmo tempo, unir o bebê à mãe, uma vez que a representa, inserindo-o no mundo simbólico, além de gerar segurança para que o bebê se afaste, gradualmente, da mãe. Esse objeto ganha importância vital ao proporcionar conforto em momentos de ansiedade, tristeza ou solidão (Winnicott, 2001b). 
O objeto transicional se localiza em uma área intermediária, não sendo percebido como interno nem externo ao indivíduo. É preciso permitir que ele fique sujo e com mau cheiro, visto que qualquer modificação de suas qualidades que não sejam feitas pelo bebê introduzirá uma ruptura de continuidade na experiência, podendo destruir seu significado e valor. Nessa relação, o bebê deixa de ser o criador do objeto e passa a manipulá-lo (Winnicott, 1975).

O destino do objeto transicional é ser gradualmente desinvestido, perdendo seu significado conforme os fenômenos transicionais se espalham pela área intermediária e cultural (Winnicott, 1975). Contudo os padrões de comportamento estabelecidos no início da vida (a maneira como a criança vai usar o objeto, as situaçóes e por quanto tempo esse uso vai se prolongar) serão estabelecidos de acordo com suas necessidades (Winnicott, 2001b) e podem persistir no decorrer da infância ou também reaparecer numa idade posterior, diante da ameaça de abandono (Winnicott, 1975).

Pode-se pensar na presença do amigo imaginário como tendo uma função bastante semelhante à do objeto transicional, visto que ele também emerge na área intermediária ao mundo externo e interno, além de auxiliar a criança na experimentação da agressividade e do amor (Klein, 1985). Eleger um objeto e ser capaz de interagir com este na área transicional é sinal de saúde, porém o mesmo não será possível para um bebê com o desenvolvimento emocional muito perturbado (Winnicott, 1975). O desenvolvimento emocional perturbado ocorre quando os cuidados que o bebê recebe do ambiente, representado pela mãe, são confusos e não estáveis. Isso dificulta que o bebê atinja os estados de integração (eu sou), personalização (a psique habita o corpo) e contato com a realidade (relaçôes objetais), aquisiçôes imprescindíveis para que o processo do amadurecimento emocional se dê. Um ambiente caótico pode parar o desenvolvimento emocional num estágio demasiadamente precoce e impossibilitar que o bebê evolua do estado de dependência absoluta (quando o bebê desconhece a sua dependência do meio, 0 a 6 meses), para a dependência relativa (quando o bebê começa a perceber sua dependência do meio, 6 até 12 a 18 meses), até atingir a independência relativa (estado no qual o indivíduo emocionalmente maduro permanece ao longo de sua vida) (Winnicott, 2001b; 1983a).

O amigo imaginário protege o desenvolvimento do eu, o senso de integridade e pode promover o suporte nas transiçóes dos estágios do desenvolvimento. Emerge no espaço potencial. Por esse motivo, está relacionado ao sentimento de onipotência, mas também à realidade objetiva (Benson \& Pryor, 1973). Diferente do objeto transicional, que também surge do espaço potencial e representa a ligação e separação da criança com a mãe, o amigo imaginário vem como representante do eu, que agora não está mais em fusão. Ainda, além de desempenhar a função de um eu transicional que externaliza aspectos de representação do eu da criança, ele auxilia no manejo de impulsos agressivos direcionados a ela mesma e a seus pais (Klein, 1985). 


\subsection{A psicose e o amigo imaginário}

Considerando que o fenômeno do amigo imaginário possibilita a confusão entre os limites entre saúde e patologia, faz-se necessária uma discussão sobre a psicose infantil. Segundo a abordagem do Manual Diagnóstico e Estatístico de Transtornos Mentais [DSM-V] (Associação Americana de Psiquiatria, 2014), a psicose pode ser entendida como um distúrbio relativo às falhas ambientais na primeira fase do desenvolvimento emocional e representa uma forma patológica de organização das defesas, que alertam a ameaça de ruptura da integração. São candidatas a tal condição as crianças com tendência hereditária (Winnicott, 2001a) e as que passaram por experiências traumáticas devido a falhas do ambiente, ocasionando uma quebra em sua continuidade de ser (Winnicott, 1999). Além disso, é característica na psicose uma frouxa conexão entre a psique, o corpo e o fracasso no estabelecimento de relações objetais. Assim, o relacionamento fica voltado para o mundo subjetivo ou não obtém sucesso em se relacionar com qualquer objeto fora do eu (Winnicott, 1999).

A ocorrência de fracassos seguidos do ambiente gera um trauma que interrompe a continuidade de ser do bebê, causando a angústia de aniquilamento. Uma experiência traumática pode acontecer pela escassez de cuidados ou por uma invasão excessiva, fazendo com que a criança reaja, ocasionando a quebra no sentimento de existir (desintegração), o que interrompe o seu processo de amadurecimento rumo à integração (Winnicott 1999; Abadi, 1998). Assim, as características clínicas vão se desenvolver de acordo com a fase do desenvolvimento em que a criança precisou reagir à falha ambiental e com a maneira com que ela pôde se defender (Winnicott, 2005a). Enquanto na neurose o indivíduo pode integrar-se e se tornar uma unidade diferenciada do que lhe é externo, na psicose o mesmo não ocorre (Winnicott, 1983b). Assim, para se defender das angústias de desintegração, faz-se uso de mecanismos de defesa primitivos (Geissmann \& Geissmann, 1993).

Dessa forma, o fracasso do cuidado do tipo materno oferecido pelo ambiente, responsável por afastar o imprevisível, ou a não sobrevivência de quem exerce esse cuidado (em geral, a mãe biológica) como objeto, que satisfaz as necessidades urgentes e é alvo dos impulsos, faz com que a capacidade de envolvimento do bebê seja perdida ou não seja mais alcançada. Essa capacidade é substituída por angústias (de desintegração) e defesas primitivas (Winnicott, 2005b). Porém, sobre a responsabilização dos pais diante do adoecimento da criança, é importante esclarecer que, por mais relacionado que esse fato possa estar com algo que vem dos pais, de forma alguma, ocorre por vontade destes (Geissmann \& Geissmann, 1993; Winnicott, 2001a). Ainda, a provisão de um ambiente satisfatório não garante que a criança alcance a maturidade, já que cada indivíduo traz consigo, ao nascer, seu potencial de desenvolvimento (Winnicott, 1983b). 
No que se refere aos manuais de classificação dos transtornos mentais, o DSM-V (Associação Americana de Psiquiatria, 2014) não contempla mais a psicose infantil em sua nosografia, encontrando-se essa psicopatologia dispersa no item que hoje é chamado "transtorno do espectro autista". Ainda segundo o DSM-V, os sintomas psicóticos da esquizofrenia surgiriam entre o fim da adolescência e 30 anos de idade. Seu início antes dessa fase é considerado raro, pois suas características, apesar de poderem estar presentes na infância, são mais difíceis de serem diagnosticados, visto que os delírios e as alucinações normalmente são mais brandos e devem ser diferenciados da expressão normal da fantasia (Associação Americana de Psiquiatria, 2014). Concordando com tal concepção, Stubbe (2008) também aponta para a dificuldade de avaliação dos sintomas psicóticos em crianças, tendo em vista que essa é uma época em que a fantasia, o pensamento ilógico e amigos imaginários se fazem presentes.

As defesas patológicas da psicose se diferenciam do emprego do amigo imaginário, pois não permitem a vida criativa, já que se encontram organizadas contra a desintegração, provenientes de falhas constantes do ambiente (Winnicott, 1999). Com isso, pode-se inferir a natureza pobre do simbolismo na estruturação psicótica, em oposição à invenção de uma companhia imaginária.

Para que haja riqueza no simbolismo, é preciso haver criatividade e esta só é possível a partir da extrema adaptação daquele que exerce o cuidado de tipo materno, ao apresentar fragmentos do mundo no momento exato em que o bebê necessita (Winnicott, 2001b). Essa sincronia da apresentação de objetos, realizada por aquele que exerce o cuidado de tipo materno, faz com que o bebê se sinta criador de tudo aquilo que o satisfaça (ilusão de onipotência/criatividade primária). Também possibilita, cada vez mais, os momentos de integração.

Dessa forma, por ser fruto da criatividade, é possível pensar o fenômeno do amigo imaginário como um aspecto saudável do desenvolvimento e não um sintoma da psicose. Essa diferenciação se faz importante visto que, conforme exposto, a literatura estrangeira demonstra que o amigo imaginário se refere a um fenômeno bastante presente na vida das crianças. Apesar disso, a busca por literatura nacional realizada pelos autores em bases de dados (SciELO, Index Psi e PePsic) encontrou poucos estudos sobre o assunto. Sobre isso, a revisão da literatura realizada por Velludo e Souza (2015) encontrou 46 referências sobre a temática, mas apenas um estudo nacional a respeito, sendo que, em nenhum desses estudos, os participantes eram profissionais da área de saúde infantil. Diante da lacuna reportada, este trabalho teve por objetivo conhecer como os profissionais da área de Psicologia e de Psiquiatria estão compreendendo, diagnosticando e tratando, se for o caso, esse fenômeno no contexto da clínica infantil. A partir disso, buscou-se contribuir não apenas para a atuação e conhecimento dos 
profissionais da área de saúde infantil, mas também para todos aqueles que têm contato com crianças (profissionais escolares, familiares, etc.).

\section{MÉTODO}

\subsection{Delineamento e participantes}

Neste estudo, foi utilizado o método clínico-qualitativo, uma vez que o objetivo era identificar e compreender um fenômeno com base na significação dada pelos sujeitos participantes. Também por esses motivos, considera-se que esta se caracteriza como uma pesquisa fenomenológica, visto que busca construir percepções da realidade pelas vivências dos indivíduos (Canzonieri, 2010). Para abordar o tema e atingir os objetivos, esta pesquisa contou com a participação de profissionais da Psicologia e da Psiquiatria.

Os dados foram coletados de entrevistas ${ }^{5}$ individuais realizadas com cinco profissionais de saúde mental infantil, sendo E1, E2 e E3 da área da Psicologia e E4 e E5 da psiquiatria. O número de entrevistados foi definido com base no processo de amostragem por saturação, finalizando a coleta de dados quando estes se tornam repetitivos e nenhuma informação nova aparece (Canzonieri, 2010; Fontanella, Ricas \& Turato, 2008). Como critérios de inclusão, era necessário que o profissional tivesse atuado na clínica infantil por, no mínimo, cinco anos ou ainda estivesse atuando, tendo ou não atendido casos em que o fenômeno se fazia presente. Todos os participantes entrevistados tinham tempo de atuação na clínica infantil superior a dez anos e empregam a psicanálise como referencial teórico para entender o desenvolvimento infantil.

Tabela 1. Características dos participantes

\begin{tabular}{|l|l|l|l|l|l|}
\hline Participantes & Profissão & $\begin{array}{c}\text { Tempo de } \\
\text { profissão }\end{array}$ & $\begin{array}{c}\text { Tempo de } \\
\text { atuação na } \\
\text { clínica infantil }\end{array}$ & $\begin{array}{c}\text { Referencial } \\
\text { teórico }\end{array}$ & $\begin{array}{c}\text { Principais } \\
\text { autores } \\
\text { estudados }\end{array}$ \\
\hline E1 & Psicólogo & 14 anos & 13 anos & Psicanálise & $\begin{array}{l}\text { Freud } \\
\text { Lacan }\end{array}$ \\
\hline E2 & Psicólogo & 20 anos & 18 anos & Psicanálise & $\begin{array}{l}\text { Françoise Dolto } \\
\text { Winnicott }\end{array}$ \\
\hline E3 & Psicólogo & 14 anos & 14 anos & Psicanálise & $\begin{array}{l}\text { Freud } \\
\text { Winnicott } \\
\text { Melanie Klein }\end{array}$ \\
\hline E4 & Psiquiatra & 17 anos & 15 anos & $\begin{array}{l}\text { Psicanálise e } \\
\text { DSM }\end{array}$ & Não referiu \\
\hline E5 & Psiquiatra & 16 anos & 13 anos & $\begin{array}{l}\text { Psicanálise e } \\
\text { DSM }\end{array}$ & $\begin{array}{l}\text { Freud } \\
\text { Winnicott }\end{array}$ \\
\hline
\end{tabular}

Fonte: Elaborado pelas autoras.

5 As entrevistas foram realizadas entre junho e setembro de 2014, no local de trabalho dos participantes. 


\subsection{Instrumentos}

Foi utilizada uma entrevista semiestruturada com os profissionais. Essa técnica permitiu que a interlocução se desenvolvesse de maneira flexível, na qual tópicos serviram como guias para que o tema fosse abordado em sua totalidade (Minayo, 2010). Assim, foram feitas questôes sobre:

a) os referenciais teóricos para entender o desenvolvimento infantil;

b) as principais características da psicose infantil;

c) o entendimento sobre o fenômeno do amigo imaginário na clínica infantil;

d) as concepções dos pais sobre o amigo imaginário;

e) as possíveis diferenças e aproximações entre o fenômeno e a psicose;

f) como o amigo imaginário se faz presente no atendimento/tratamento da criança.

\subsection{Procedimentos e considerações éticas}

Inicialmente, o projeto de pesquisa foi submetido ao Comitê de Ética em Pesquisa com Seres Humanos da Universidade com a qual as pesquisadoras têm vínculo. Após sua aprovação (sob protocolo 30758014.0.0000.5346), foi feito contato com os profissionais para explicar o estudo, verificando sua disponibilidade e interesse em participar. Os profissionais foram recrutados em clínicas de atendimento à criança em uma cidade do interior do Rio Grande do Sul. Uma vez esclarecidos os objetivos e procedimentos da pesquisa, e conferidos os critérios de inclusão, os participantes que aceitaram participar do estudo assinaram o termo de consentimento livre e esclarecido, como previsto pelo Conselho Nacional de Saúde através da Resolução no 466/2012. A entrevista foi agendada conforme disponibilidade do profissional, em seu consultório particular ou em local de sua preferência. As conversas foram gravadas e posteriormente transcritas para análise qualitativa dos dados.

\subsection{Análise dos dados}

Os dados coletados nas entrevistas foram analisados e relacionados com a revisão teórica prévia. Para isso foi usada a análise de conteúdo, na qual os dados são interpretados na perspectiva dos entrevistados e relacionados com o referencial teórico, a fim de produzir conhecimento (Campos \& Turato, 2009). Seguiu-se a forma de análise de conteúdo aberta proposta por Rey e Luís (2011), 
que transcende toda a rigidez do método e o transforma em um processo de construção por meio da interpretação das informações pelos pesquisadores. Segundo os autores: "Essa forma de análise de conteúdo é aberta, processual e construtiva e não pretende reduzir o conteúdo a categorias concretas restritivas" (Rey \& Luís, 2011, p. 146). Dessa forma, foi possível identificar como os participantes compreendiam a presença do amigo imaginário na infância; como esse fenômeno era concebido pelos pais; como se fazia presente na clínica; e as semelhanças e diferenças entre o fenômeno do amigo imaginário e os sintomas da psicose infantil, categorias que permitiram as discussões que se seguem.

\section{RESULTADOS E DISCUSSÃO}

A interação com amigos imaginários é considerada comum e como um componente do desenvolvimento emocional e cognitivo (Taylor, 1999). Em acordo com a teoria, os dois psiquiatras entrevistados (E4 e E5) relataram terem recebido pacientes que vivenciaram tal fenômeno. No entanto os três psicólogos (E1, E2 e E3) mencionaram que não era comum que ele chegasse até os seus consultórios. E1 eE3 disseram nunca terem atendido crianças que se relacionassem com amigos imaginários. Apesar disso, os dois tiveram contato com o fenômeno pela interação com crianças de seu convívio pessoal. Ainda sobre a frequência com que o fenômeno do amigo imaginário ocorre, E2 referiu: "Eu não sei se é raro de ocorrer ou se as pessoas não mencionam". Sobre essa divergência entre prática e literatura encontrada nas entrevistas dos psicólogos participantes, podese questionar se há relação com o fato de nenhum deles ter tido a oportunidade de estudar esse tema durante sua formação. Apesar de não terem estudado de maneira aprofundada, os mesmos profissionais que mencionaram a presença do fenômeno na clínica (E4 e E5) disseram já terem abordado o tema: "Não de uma forma específica, assim, 'estudar amigo imaginário', tu acaba vendo dentro dos assuntos gerais do desenvolvimento" (E5).

A presença do amigo imaginário geralmente se evidencia por meio do diálogo com os pais, segundo E2, E4 e E5. Pela experiência dos profissionais, esse relato dos pais vem como forma de informação ou questionando a normalidade dessa fantasia. Segundo E4, "A principal preocupação dos pais, em geral, é com a psicose. É associar o aparecimento de um amigo que eles não veem com um sintoma psicótico". Segundo Taylor (1999), apesar de ser uma maneira equivocada de entender esse fenômeno, ele pode ser considerado pelo público leigo como um sinal de perturbação psíquica, causando preocupação em alguns pais. Por outro lado, E5 mencionou que é raro os pais se preocuparem: "Acho que eles já tenham 
talvez uma coisa cultural, assim, de que isso é algo positivo, que tem a ver com a criatividade da criança".

Sobre a influência da cultura, E1 comentou o papel da televisão na formação das concepções acerca do amigo imaginário. Ele falou do episódio Amigo faz de conta (Davies \& Parker, 2006), do desenho infantil A porquinha Peppa, no qual o fenômeno é tratado como um acontecimento saudável. Tal concepção se opõe à visão presente nas primeiras pesquisas sobre o fenômeno (Taylor, 1999), em que a criação de amigo imaginário era vista como sinal de patologia, o que permite supor que há mais informações positivas sobre esse fenômeno sendo difundidas nas mídias, que hoje é percebido como saudável. Isso vai ao encontro da hipótese levantada por E2, de que a relativa ausência do amigo imaginário na clínica infantil pode estar ligada ao fato de esse fenômeno não despertar preocupação nos cuidadores.

A concepção e criação dos amigos imaginários também se relaciona com as crenças pessoais dos pais. Essa observação apareceu na entrevista de E1, quando ela contou sua experiência pessoal com o fenômeno. O contato ocorreu por meio de uma prima que tinha um amigo imaginário: "Eu lembro que essa minha tia, meu tio, ficaram meio preocupados no início e tal. Eu acho que ela era espírita, então ela achou mais por essa via”. E1 comentou, então, sobre a crença espírita, que postula que crianças de até 7 anos são mais sensíveis e, por isso, seriam capazes de "olhar os espíritos que habitam entre a gente". Esse entendimento da participante vai ao encontro do proposto por Singer e Singer (1990), que uma das formas de os adultos significarem a interação das crianças com amigos imaginários é por crenças espíritas.

Algumas pessoas também podem ler o amigo imaginário como um sinal de criatividade (Taylor, 1999; Hoff, 2005). E1 mencionou essa concepção em sua entrevista, quando comentou que sua prima que interagia com um amigo imaginário se tornou uma pessoa muito criativa e proativa. Além de E1, E3 e E5, também relacionam a criação de amigos imaginários com a criatividade infantil.

É algo muito mais da criatividade, do desenvolvimento saudável do que qualquer outra (E3).

Isso é algo positivo, que tem a ver com a criatividade da criança, com a capacidade da criança de ficar sozinha, com o processo de dependência absoluta para o processo mais de independência, pra um amadurecimento. Que é uma forma com que a criança talvez crie aquela situação, aquele espaço pra conseguir se desenvolver e se separar dos pais. Tolerar a ausência dos pais. Uma forma de criatividade (E5).

Todos os participantes desta pesquisa consideraram a interação com amigos imaginários um recurso que pode ser utilizado pela criança no decorrer do 
desenvolvimento normal. Logo, as entrevistas apontaram para uma concordância com a concepção de Taylor e Mottweiler (2008). E1, ao comentar sobre pacientes que faziam uso de brinquedos personificados, destacou ser:

Um fenômeno natural da infância, de uma etapa de transição, [...] as características que se coloca nesses bichinhos, nessas bonecas, geralmente são ou características com as quais a criança se identifica em termos de idade, ou quando ela tá fazendo uma diferenciação.

Para E1, a interação com esses objetos permite elaborações simbólicas e imaginárias. Adotando a definição de "amigo imaginário" de alguns autores (Singer \& Singer, 1990; Taylor et al., 2004; Taylor \& Mottweiler, 2008), a qual inclui brinquedos que foram personificados pela criança e com os quais ela interage com frequência, pode-se considerar esses brinquedos citados por E1 como amigos imaginários.

A época em que a interação com amigos imaginários é mais comumente observada está entre a faixa etária dos 2 aos 6 anos de idade (Singer \& Singer, 1990). Quando questionado sobre a faixa etária para a criação desses companheiros, E1 mencionou de 4 a 7 anos, E3 de 2 a 6, E4 de 3 a 5, e E5 de 3 a 6 anos de idade. Diante dessa questão, para E4 é essencial ter flexibilidade: "Um amigo imaginário é normal quando ele tá em consonância com a faixa etária da criança onde é esperado que o fenômeno aconteça, com um pouco de flexibilidade, na clínica a gente tem que levar em conta isso". Assim, mesmo com pequenas variaçôes entre as respostas dadas, pode-se considerar que todos os participantes estão em consenso entre si e com a faixa etária anteriormente proposta por Singer e Singer (1990).

Em sua entrevista, E2 mencionou que fazer uso de um fenômeno transicional é:

Usar um objeto, ou algo do tipo, assim, como um auxílio na separação da mãe. [...] Elas [as crianças] vão se utilizar disso, então, nesse momento, pra buscar um consolo, pra buscar uma espécie de conforto por essa ausência da pessoa de referência.

O objeto transicional tem importância vital para a criança, por trazer conforto em momentos de ansiedade, tristeza ou solidão (Winnicott, 2001b). Para os três psicólogos entrevistados nessa pesquisa o amigo imaginário tem algumas funções semelhantes às do objeto transicional. Essa aproximação foi feita claramente por E3, que considera os dois fenômenos uma criação da criança, com certa duração e que deixam de existir quando não têm mais finalidade: 
O objeto transicional é a primeira posse não eu do bebê, a primeira criação, e ele tem todas as características importantes praquele bebê [...]. Aí ele deixa de existir quando ele não tem mais finalidade, que ele ajuda na questão de separação do bebê e da mãe. E observando algumas questões, observando na prática, algumas questôes do amigo imaginário com crianças, assim, o que eu observo também é uma criação, dura um tempo, e naturalmente deixa de existir (E3).

Em concordância com Taylor (1999), a criação do amigo imaginário pode surgir como uma resposta adaptativa que parte da criança para lidar com questôes difíceis de sua vida. Conforme já mencionado, para Benson e Pryor (1973), o amigo imaginário assemelha-se ao objeto transicional visto que oferece suporte para a criança, protegendo a autoestima, a integração e a representação do eu. Para E2:

O amigo imaginário também me parece que serviria nesse sentido, assim, como uma busca de consolo [...] Talvez esse amigo ajude de alguma forma. Essa fantasia de que alguém tá com ela, ajude a lidar com situações que fazem parte do desenvolvimento, mas que são difíceis (E2).

Os participantes não indicaram considerar a presença do amigo imaginário como sinal de patologia. Apesar disso, mencionaram ser importante investigar essa interação, pois, por meio dela, a criança expressa seu desejo e mostra seu mundo interno:

Tem a ver sempre com um significado (E5).

Tá ali como um sintoma, ou atrapalhando a criança, ou sendo usado pela criança como uma forma de compensação patológica de alguma situação, ou pra tentar se proteger de alguma situação familiar patológica (E4).

Por entender o amigo imaginário como algo que vem para aplacar a ansiedade, E2 referiu a importância de verificar se há algum fator estressor que justifique a criação dessa fantasia. Ainda, ele propôs que, em casos mais sérios, a criança desenvolve sintomas como forma de pedir um olhar mais atencioso. Segundo esse participante, se isso ocorrer, normalmente os pais procuram atendimento psicológico. E2 citou como exemplo de causadores de ansiedade para criança a ausência muito prolongada dos pais e problemas familiares.

Como já mencionado, a interação com amigos imaginários não indica que a criança esteja com dificuldades psicológicas, mas é comum que crianças inseridas em ambientes com fatores estressores criem amigos imaginários (Taylor, 1999). A fantasia funciona como um suporte para a criança, logo, um amigo imaginário auxilia a criança na superação de seus problemas (Taylor, 1999; Majors, 2013). 
Além disso, esses companheiros facilitam a comunicação. É mais fácil para a criança expressar seus sentimentos e falar de assuntos que são difíceis para ela por meio do amigo imaginário (Taylor, 1999). Isso apareceu na entrevista de E3, Segundo ele, "Talvez a forma que ela [a criança] consegue de falar com aquela mãe seja através do amigo imaginário". Às vezes, a maneira que a criança encontra de falar com um adulto é pela conversa com seu companheiro imaginário (Taylor, 1999).

Quando questionados sobre possíveis semelhanças e divergências entre o amigo imaginário e os sintomas da psicose, E1 e E3 comentaram sobre a pobreza do simbólico na psicose. E1 referiu que a criança psicótica demonstra "dificuldade em fazer um jogo simbólico, de criar personagens, de simular". Segundo esse participante, ela até pode se interessar pelos brinquedos, mas tem dificuldades em brincar. Para exemplificar:

Tu pode ter o cavalo como cavalo, tu pode ter o pedaço de vassoura como cavalo e tu pode ter nada como cavalo. Se a literatura trouxer o amigo imaginário como esse nada como cavalo, sem essa constância que na minha cabeça era, nossa, isso é muito natural. É uma passagem boa. Até diria que é uma criança mais criativa. Tem essa capacidade de tá enxergando ali o que não tá pra brincar, entende. E ela vai se constituir em todos os termos de linguagem, de relação com o outro, brincando. [...] Enquanto no campo da psicose, seria mais uma aproximação pra cá, do cavalo como cavalo, entende. De não ter tanto essas possibilidades imaginárias e simbólicas de fazer de qualquer coisa, ou nenhuma coisa, um cavalo (E1).

[Diferentemente da psicose], o que que eu acredito que acontece: no amigo imaginário existe o simbólico (E3).

Para Winnicott (1999), o impulso criativo só aparece a partir do estado de não integração, que faz parte do desenvolvimento emocional saudável. Já na psicose, a organização de defesas primitivas, que protege o ser de novas experiências traumáticas, causa a desintegração e não permite a vida criativa. Logo, há uma pobreza simbólica na estruturação psicótica.

No fenômeno do amigo imaginário, existe claramente a diferenciação entre o eu e o outro, já na alucinação essa fronteira é confusa. E1, E2 e E3 também chamaram a atenção para o fato de a alucinação não buscar uma interação com o meio e se encontrar descolada da realidade. Por sua vez, o brincar com o amigo imaginário se adapta conforme o ambiente: "[ $\mathrm{Na}$ alucinação] não tá buscando uma interação com o meio, uma troca [...] e não tem a ver com a realidade. [...] Uma criancinha que tá lidando com um amigo imaginário ela vai reagir conforme o meio ambiente também" (E2).

A análise das entrevistas dos psicólogos e dos psiquiatras permitiu conhecer como os profissionais compreendiam a presença de amigos imaginários na 
infância. Todos os participantes interpretavam e tratavam o fenômeno como algo saudável, relacionado a possíveis dificuldades com as quais as crianças se depararam no decorrer do desenvolvimento, ou como uma forma de expressão lúdica. Apesar disso, algumas falas salientaram a importância de dar atenção à essa fantasia, visto que crianças podem vir a utilizá-la como recurso para lidar com estressores presentes em seu ambiente (Taylor, 1999). Ainda, nenhum entrevistado entendia a interação com amigos imaginários como um sintoma da psicose infantil. A análise das entrevistas também permitiu verificar que a nosografia psicanalítica permeou as reflexóes dos profissionais, em que a compreensão do desenvolvimento saudável e suas distinções das características da psicopatologia (isto é, psicose), possibilita-lhes oferecer a escuta necessária a cada caso.

Neste estudo, apresentaram-se como limitações o número reduzido de participantes, que totalizou cinco profissionais da área da saúde mental infantil, e o fato de que todos eles compartilhavam a mesma abordagem teórica (psicanalítica). Tais características permitiram fornecer apenas um recorte acerca do entendimento dos profissionais da saúde mental sobre a presença do amigo imaginário na infância, o que sugere a necessidade de novas pesquisas a respeito.

\section{CONSIDERAÇÕES FINAIS}

A literatura psicológica revisada apresenta evidências de que a presença de amigos imaginários na vida das crianças é algo comum, saudável e positivo (Klein, 1985; Majors, 2013; Shapiro et al., 2006; Singer \& Singer, 1990; Taylor, 1999; Taylor \& Mottweiler, 2008). Essa concepção estava igualmente presente nos relatos de todos os profissionais entrevistados, juntamente com o entendimento de que a criança pode encontrar nessa fantasia um recurso para lidar com fatores estressores presentes no ambiente onde vive.

Ao contrário do esperado, o fenômeno não se faz tão presente nos consultórios psiquiátricos e raramente aparece nos psicológicos. Tal padrão pode se dever ao fato de que esses companheiros imaginários despertam poucas preocupaçôes nos pais e, ou, cuidadores, uma vez que o fenômeno não é citado como motivo de procura para os atendimentos clínicos. Geralmente essa fantasia aparece por meio do discurso dos pais no decorrer do tratamento, podendo denotar uma simples informação ou questionamento sobre a criação desse fenômeno ser saudável ou não.

O discurso dos profissionais indicou que estes não entendem que a interação com amigos imaginários, por si só, demande tratamento. Eles diferenciavam o fenômeno de sintomas como alucinação e delírio, comuns à psicose infantil, 
com facilidade. Ainda assim, os profissionais apontaram a importância de se investigar essa interação, a fim de se compreender se essa fantasia se faz presente pela própria diversão que essa interação proporciona ou se a criança faz uso dela como suporte para lidar com alguma situação real. Finalmente, a presença da fantasia nos atendimentos foi apontada como um facilitador da comunicação, atuando como um recurso para a investigação e o entendimento da realidade psíquica da criança.

A população desta pesquisa, profissionais de saúde mental, é distinta das normalmente vistas nos estudos acerca do tema, como crianças que interagem com amigos imaginários, os pais dessas crianças, ou adultos que criaram esses companheiros na infância (Velludo \& Souza, 2015). Infere-se que conhecer a concepção desses profissionais acerca do fenômeno estudado se faz especialmente importante por atuarem na atenção à saúde mental infantil e serem referências para a população nesse assunto. Acredita-se que o desenvolvimento de novas pesquisas, que façam uso de diferentes fontes de informação e investiguem outras populações, possam vir a contribuir para um conhecimento mais completo sobre a interação com amigos imaginários. Desse modo, procurou-se complementar a literatura existente, e escassa no caso da produção nacional, ao estudar o amigo imaginário por uma nova perspectiva. 


\section{REFERÊNCIAS}

Abadi, S. (1998). Transiçôes: o modelo terapêutico de D. W. Winnicott. São Paulo: Casa do Psicólogo.

Associação Americana de Psiquiatria. (2014). Manual diagnóstico e estatístico de transtornos mentais: DSM-V. Porto Alegre: Artmed.

Benson, R. M. \& Pryor, D. B. (1973). When friends fall out: developmental interference with the function of some imaginary companions. Journal of American Psychoanalytic Association, 21, 457-473.

Bouldin, P. \& Pratt, C. (2002). A systematic assessment of the specific fears, anxiety level, and temperament of children with imaginary companions. Australian Journal of Psychology, 54(2), 79-85.

Campos, C. J. G. \& Turato, E. R. (2009). Análise de conteúdo em pesquisas que utilizam metodologia clínico-qualitativa: Aplicação e perspectivas. Revista Latino-Americana de Enfermagem, 17(2), 259-264.

Canzonieri, A. M. (2010). Metodologia da pesquisa qualitativa na saúde. Petrópolis: Vozes.

Davies, P. (Produtor) \& Parker, C. (Escritor). (2006). Amigo faz de conta [Séries de televisão]. Recuperado a partir de https://www.youtube.com/ watch?v=5MrPz9yqQFg

Fontanella, B. J. B., Ricas, J. \&, Turato, E. R. (2008). Amostragem por saturação em pesquisas qualitativas em saúde: Contribuições teóricas. Caderno de Saúde Pública, 24(1), 17-27.

Geissmann, P. \& Geissmann, C. (1993). A criança e sua psicose. São Paulo: Casa do Psicólogo.

Gleason, T. R. (2004). Imaginary companions and peer acceptance. International Journal of Behavioral Development, 28(3), 204-209.

Harter, S. \& Chao, C. (1992). The role of competence in children's creation of imaginary friends. Merrill-Palmer Quarterly, 38(3), 350-363.

Hoff, E. V. (2005). Imaginary companions, creativity, and self-image in middle childhood. Creativity Research Journal, 17(2-3), 167-180.

Klein, B. R. (1985). A child's imaginary companion: a transitional self. Human Sciences Press, 13(3), 272-282. 
Majors, K. (2013). Children's perceptions of their imaginary companions and the purposes they serve: an exploratory study in the United Kingdom. Childhood, 20(4), 550-565.

Minayo, M. C. de S. (2010). O desafio do conhecimento: pesquisa qualitativa em saúde. São Paulo: Hucitec.

Pearson, D., Rouse, H., Doswell, S., Ainsworth, C., Dawson, O., Simms, K., . . Faulconbridge, J. (2001). Prevalence of imaginary companions in a normal child population. Child: Care, Health and Development, 27(1), 13-22.

Resolução no 466, de 12 de dezembro (2012, 12 dezembro). O Plenário do Conselho Nacional de Saúde em sua 240a Reunião Ordinária, realizada nos dias 11 e 12 de dezembro de 2012, no uso de suas competências regimentais e atribuições conferidas pela Lei no 8.080, de 19 de setembro de 1990, [...]. Diário Oficial da União, Brasília, no 466, 12 dez. 2012. Recuperado a partir de http://bvsms.saude.gov.br/bvs/saudelegis/cns/2013/res0466_12_12_2012. html

Rey, G. \& Luís, F. (2011). Pesquisa qualitativa em psicologia: caminhos e desafios. São Paulo: Cengage Learning.

Seiffge-Krenke, I. (1997). Imaginary companions in adolescence: sign of a deficient or positive development? Journal of Adolescence, 20, 137-154.

Shapiro, H. L., Prince, J. B., Ireland, R. \&, Stein, M. T. (2006). A dominating imaginary friend, cruelty to animals, social withdrawal, and growth deficiency in a 7-year-old girl with parents with schizophrenia. Journal of Developmental \& Behavioral Pediatrics, 27(3), 24-29.

Singer, D. G. \& Singer, J. L. (1990). Imaginary playmates and imaginary worlds. In D. G. Singer \& J. L. Singer, The house of make-believe: children's play and the developing imagination (pp. 89-116). Cambridge: Harvard University Press.

Stubbe, D. (2008). Psiquiatria da infância e adolescência. Porto Alegre: Artmed.

Taylor, M. (1999). Imaginary companions and the children who create them. New York: Oxford University Press.

Taylor, M., Carlson, S., Maring, B. L., Gerow, L. \&, Charley, C. M. (2004). The characteristics and correlates of fantasy in school-age children: imaginary companions, impersonation, and social understanding. Developmental Psychology, 40(6), 1173-1187. 
Taylor, M. \& Mottweiler, C. M. (2008). Imaginary companions: pretending they are real but knowing they are not. American Journal of Play, 1, 47-54.

Velludo, N. B. \& Souza, D. H. (2015). A criação de amigos imaginários: uma revisão de literatura. Psico, 46(1), 25-37.

Winnicott, D. W. (1975). Objetos transicionais e fenômenos transicionais. In D. W. Winnicott. O brincar e a realidade (pp. 13-44). Rio de Janeiro: Imago.

Winnicott, D. W. (1983a). Da dependência à independência no desenvolvimento do indivíduo. In D. W. Winnicott. $O$ ambiente e os processos de maturação: estudos sobre a teoria do desenvolvimento emocional (pp. 38-54). Porto Alegre: Artmed.

Winnicott, D. W. (1983b). Teoria do relacionamento paterno-infantil. In D. W. Winnicott. O ambiente e os processos de maturação: estudos sobre a teoria do desenvolvimento emocional (pp. 38-54). Porto Alegre: Artmed.

Winnicott, D. W. (1999). O conceito de indivíduo saudável. In D. W. Winnicott. Tudo começa em casa (pp. 3-22). São Paulo: Martins Fontes.

Winnicott, D. W. (2000). Da pediatria à psicanálise: obras escolhidas. Rio de Janeiro: Imago.

Winnicott, D. W. (2001a). Os efeitos da psicose sobre a vida familiar. In D. W. Winnicott. A familia e o desenvolvimento individual (pp. 89-100). São Paulo: Martins Fontes.

Winnicott, D. W. (2001b). O primeiro ano de vida: concepções modernas do desenvolvimento emocional. In D. W. Winnicott. A família e o desenvolvimento individual. (pp. 3-20). São Paulo: Martins Fontes.

Winnicott, D. W. (2005a). A psicologia da separação. In D. W. Winnicott. Privação e delinquência (pp. 149-152). São Paulo: Martins Fontes.

Winnicott, D. W. (2005b). O desenvolvimento da capacidade de envolvimento. In D. W. Winnicott. Privação e delinquência (pp. 111-117). São Paulo: Martins Fontes.

Winnicott, D. W. (2012). A mãe dedicada comum. In D. W. Winnicott. Os bebês e suas mães (pp. 1-11). São Paulo: WMF, Martins Fontes. 